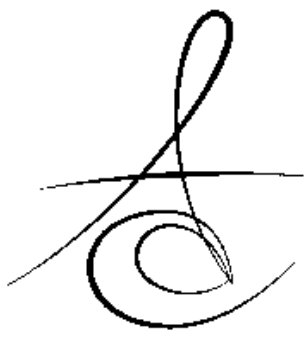

\title{
YENİ SONİK SİSTEM VİBRİNGE İLE FARKLI İRRİGASYON SİSTEMLERİNİN KÖK KANALLARINDAN KALSİYUM HİDROKSİT UZAKLAŞTIRMA ETKİNLİKLERİNİN KARȘILAȘTIRILMASI
}

\section{COMPARISON OF CALCIUM HYDROXIDE REMOVAL ACTIVITIES FROM ROOT CANALS OF NEW SONIC SYSTEM VIBRINGE AND DIFFERENT IRRIGATION SYSTEMS}

\author{
Dr. Öğr. Üyesi Banu ARICIOĞLU*
}

Dr. Öğr. Üyesi Ömer HATİPOĞLU**

Makale Kodu/Article code: 3795

Makale Gönderilme tarihi: 17.07.2018

Kabul Tarihi: 14.02 .2019

\section{öz}

Amaç: $\mathrm{Bu}$ çalışmanın amacı, Vibringe, EndoVac, pasif ultrasonik (PUI) ve geleneksel şırınga irrigasyonunun (GSI) kök kanallarından kalsiyum hidroksit (CH) uzaklaştırma etkinliklerinin taramalı elektron mikroskop (SEM) yardımı ile değerlendirilmesidir.

Gereç ve Yöntem: Bu çalışma için 70 adet tek köklü insan mandibular premolar diş kullanıldı. Örnekler ProTaper döner sistem ile F4'e kadar prepare edildi ve kalsiyum hidroksit ile dolduruldu. Bir hafta sonra, kalsiyum hidroksit kök kanallarından GSI (Grup 1), Vibringe (Grup 2) , EndoVac, (Grup 3) ve PUI (Grup 4) yöntemleri kullanılarak uzaklaştırıldı. İşlemler sırasında, her örnek için toplamda altı dakika boyunca (aktif ve pasif irrigasyon) $2.5 \mathrm{~mL} \% 2.5^{\prime}$ lik NaOCI ve ardından $2.5 \mathrm{~mL}$ 'lik $\%$ 17'lik EDTA kullanıldı. Kalan kalsiyum hidroksit miktarının değerlendirilmesi için kökler uzunlamasına ikiye ayrıldı ve $x 50$ ve $x 1000$ büyütme altında SEM'de incelendi. Veriler Kruskal-Wallis ve Mann-Whitney $U$ testleri ile istatistiksel olarak analiz edildi $(a=0.05)$.

Bulgular: Çalışmada kullanılan yöntemlerinden hiçbirisi kök kanal duvarlarından kalsiyum hidroksit medikamentini tamamen uzaklaştıramadı..

GSI sonrasında kanal duvarlarında en fazla kalsiyum hidroksit artığına rastlanırken, Vibringe, EndoVac ve PUI yöntemleri arasında anlamlı fark tespit edilmedi.( $p>0.05)$ Bununla birlikte GSI yönteminde apikal bölgede, koronal ve orta üçlüye göre anlamlı oranda daha fazla kalsiyum hidroksit artığına rastlanıldı. ( $p=0.017)$ Vibringe, EndoVac ve PUI yöntemlerinin temizleme etkinliği ise kanal üçlü bölgelerine göre anlamlı farklılık göstermedi.

Sonuç: Kök kanallarından kalsiyum hidroksit uzaklaştırmada Vibringe, EndoVac ve PUI yöntemleri birbirlerine benzer temizleme etkinliği göstermiş ve bu üç teknik de GSI metodundan daha başarılı bulunmuştur.

Anahtar kelimeler: Kalsiyum hidroksit, Vibringe, EndoVac, Pasif Ultrasonik İrrigasyon, SEM

\section{ABSTRACT}

Aim: The aim of this study was to evaluate the removal efficiencies of calcium hydroxide $(\mathrm{CH})$ from the root canals using Vibringe, EndoVac, passive ultrasonic (PUI) and conventional needle irrigation (GSI) by means of scanning electron microscopy (SEM).

Materials and Methods: Seventy single-rooted human mandibular premolar teeth were used for this study. The samples were prepared with the Protaper rotary system up to F4 and filled with calcium hydroxide. One week later, Calcium hydroxide was removed from the root canals with the several irrigation methods as follows: GSI (Group 1), Vibringe (Group 2), EndoVac (Group 3), PUI (Group 4). During the irrigation procedure, for each sample, $2.5 \mathrm{~mL}$ of $2.5 \% \mathrm{NaOCl}$ followed by $2.5 \mathrm{~mL}$ of $17 \%$ EDTA was used for six minutes totally (active and passive irrigation). For the evaluation of remaining calcium hydroxide, the roots were split longitudinally and evaluated under SEM at $x 50$ and $x 1000$. Data were analyzed statistically by Kruskal-Wallis and Mann-Whitney $U$ tests $(a=0.05)$.

Results: None of the methods used in the study could completely remove the calcium hydroxide medication from the root canal walls. Although the most residuel calcium hydroxide was observed on the canal walls after GSI irrigation, there was no significant difference between Vibringe, EndoVac and PUI methods ( $p>0.05$ ). However, GSI method showed significantly more calcium hydroxide residues in the apical region $(p=0.017)$ than the coronal and middle area. The cleaning efficiency of the Vibringe, EndoVac and PUI methods were not significantly different in root canal areas.

Conclusions: In terms of calcium hydroxide removal from root canals, Vibringe, EndoVac and PUI methods were found to be more effective than the GSI; however, there was no significant difference could be detected between each other.

Key Words: Calcium Hydroxide, Vibringe, EndoVac, Passive Ultrasonic İrrigation, SEM

\footnotetext{
"Recep Tayyip Erdogan Univeristesi, Diş hekimliği Fakültesi, Endodonti AD, Rize.

${ }^{* *}$ Sütçü İmam Universitesi, Diş hekimliği Fakültesi, Restoratif Diş Tedavisi AD, Kahramanmaraş
} 


\section{GİRIŞ}

Kök kanal tedavisinin temel amacl, enfekte kök kanallarını maksimum seviyede temizleyerek mevcut enfeksiyonun elimine edilmesi ve sonradan gelişebilecek enfeksiyonların önlenmesidir. ${ }^{1}$ Farklı şekillendirme teknikleri ve döner nikel-titanyum sistemlerinin kullanımına rağmen kök kanal anatomisinin karmaşık yapısından dolayı aksesuar ve yan kanal, apikal delta, kanal istmusları gibi anatomik yapılarda ulaşılamayan alanlar kalabilmektedir. Bunun gibi kök kanal temizliğinin tam olarak gerçekleşemediği ve ilave dezenfeksiyon uygulamalarının gerekli olduğu durumların üstesinden gelebilmek için kanal içi medikament kullanımı önerilmiştir. ${ }^{2}$

Kalsiyum hidroksit; antimikrobiyal etkisi, organik doku çözücü özelliği ve toksinleri etkisiz hale getirme gibi pek çok olumlu özellikleri nedeniyle tercih edilen bir kanal içi medikamenttir. ${ }^{3}$ Ancak, kalsiyum hidroksit artıklarının kanal dolgu patlarının hem dentine bağlanma etkisini, hem de fiziksel özelliklerini olumsuz yönde etkilemesinden dolayı kök kanallarını daimi olarak doldurmadan önce mümkün olduğunca uzaklaştırıması gerekmektedir. ${ }^{4} \mathrm{Bu}$ amaç doğrultusunda değişik irrigasyon solüsyonları ve pek çok mekanik teknik geliştirilmiştir.

Klasik endodonti kitaplarında 'basit bir uyguma' veya 'genel bir rehber' olarak bahsedilen şırınga-iğne ile yapılan geleneksel irrigasyon yöntemi diş hekimleri ve endodontistler tarafından hala en yaygın olarak kullanılan ve kabul gören bir yöntemdir. ${ }^{5}$ Yöntem uygulanması aşamasında hekime kök kanalı içerisinde iğne penetrasyon derinliği yanı sıra kullanılan irrigasyon solüsyonu hacmini de kontrol edebilme imkanı sağlar. ${ }^{6}$ Ancak yöntemin uygulanması sırasında meydana gelen basınç artışı ve akış hızı kök ucundan taşmalara ve periapikal dokularda irritasyonlara sebep olabilir. ${ }^{7}$ Bunun yanı sıra, dental şırınga pistonunun küçük yüzey alanı ve başparmağın basıncı birleşmesiyle istenmeyen ve beklenmedik kazalar meydana gelebilir. $^{8}$

EndoVac, Discus Dental tarafından (Tulsa, Oklahoma)geleneksel iğne ile irrigasyonun aksine negatif basınç tekniğinin kullanıldığı yeni bir yaklaşım olarak tanıtılmıştır. ${ }^{9} \mathrm{Bu}$ sistemin geliştirilmesindeki başlıca amaç, şekillendirilen kök kanalları içerisinde periapikal dokulara herhangi bir taşma riski söz konusu olmaksızın çalışma boyuna kadar bol miktarda irrigasyon solüsyonunun iletilmesinin sağlanmasıdır. ${ }^{10}$ Sistem irrigasyon solüsyonunun pulpa odasına gönderilmesi ve eş zamanlı olarak kök kanallarından tahliye edilmesi şeklinde çalışmaktadır. ${ }^{11}$

PUI işlemi ilk olarak Weller ve ark (1980) tarafından tanımlanmıştır. ${ }^{12}$ Çalışma prensibi, Cihaz tarafından 25-30 kHz frekans aralığında üretilen ultrasonik enerjinin kök kanalları içerisinde serbest salınım yapan eğe vasıtasıyla irrigasyon solüsyonuna iletilmesi ve böylece kavitasyon etkisi meydana getirilmesi esasına dayanır. ${ }^{13}$ Bazı araştırmacılar, kök kanal sisteminden bakterileri temizleyen en iyi yöntemin ultrasonik ile irrigasyon yöntemi olduğunu belirtmişler ${ }^{14}$ bazıları da ultrasoniklerle kombine kullanımda NaOCl'in klasik önerilen konsantrasyonunun yarısının kullanımını bile yeterli olabileceğini belirtmişlerdir. ${ }^{15}$

Sonik yıkama sistemleri adı altında Hollandalı bir firma tarafından piyasaya sürülen Vibringe (Cavex Holland BV, Haarlem,Netherlands), manuel ve sonik aktivasyonun kombine edildiği bir sistemdir. $10 \mathrm{~mL}$ 'lik Luer-lock şırıngaya uyumlu halka şeklinde bir pistondan ve kablosuz ve şarj edilebilir bir bataryadan oluşur. Halkanın iç kısmındaki butona başparmakla basılması ile iğnede yaklaşık $150 \mathrm{~Hz}$ titreşim sıkığında vibrasyon meydana gelir. Şırınga, çeşitli boyutlarda irrigasyon iğneleriyle kombine bir şekilde kullanılabilir. $\mathrm{Bu}$ sistem irrigasyon solüsyonunun tek adımda sonik aktivasyonu ve dağılımına izin verir. Şırıngaya bağlı iğne gibi irrigasyon solüsyonu da sonik olarak aktive edilir. ${ }^{16}$

Bu çalışmanın amacı, sonik irrigasyon yönteminde en son piyasaya sürülmüş Vibringe ile farklı mekanizmalarla çalışan güncel (EndoVac, PUI) ve geleneksel irrigasyon yöntemlerinin (GSI), kök kanallarından kalsiyum hidroksit uzaklaştırma etkinliğinin in- vitro ortamda karşılaştırmalı olarak incelenmesidir. Başlangıç hipotezi gruplar arasında fark olmadığı şeklinde kurulmuştur.

\section{MATERYAL ve METOD}

Bu çalışmaya Recep Tayyip Erdoğan Üniversitesi Tıp Fakültesi Klinik Araştırmalar Etik Kurul Komisyonu tarafından etik kurul onayı alınarak başlandı (2017/07). Çalışmada kullanılmak amacı ile ortodontik veya periodontal nedenlerle yeni çekilmiş benzer kök kanal morfolojisine sahip 70 adet tek ve 
düz köklü insan alt çene küçük azı dişleri seçildi. Seçilen dişler arasından çürük, çatlak, kök kanal kalsifikasyonu ve apeksi açık olanlar çalışmadan çıkartıldı. Kök yüzeylerindeki sert ve yumuşak doku artıkları periodontal küret yardımı ile temizlenip dişler kullanılıncaya kadar +4 C'de ve \%100 nemli ortamda, $\% 0.02$ sodyum azid ile desteklenen \%0.9 NaCl solüsyonu içerisinde bekletildi. Her bir dişin koronal kısımları mine-sement birleşim seviyesinin altından su soğutması eşliğinde uzaklaştırıldı ve her bir kökün boyu $16 \pm 0.5$ mm'ye sabitlendi. Çalışma uzunluğu bu boydan $1 \mathrm{~mm}$ kısa olacak şekilde belirlendi. \#10 K tipi eğe (Mani Inc., Tochigi, Japonya) ile apikal açıklık kontrol edildi. Elde edilen köklerin apikal kısımları pembe mum ile kapatıldı ve polivinilsiloksan ölçü maddesi ile plastik kaplara yerleştirildi. Preparasyon işlemleri üretici firmanın talimatları doğrultusunda Protaper Unıversal (Dentsply Maillefer, Ballaigues, İsviçre) eğe sistemleri ile F4'e kadar gerçekleştirildi. İşlem boyunca her eğe arasında kök kanalları $1 \mathrm{~mL}$ $\% 2.5^{\prime}$ lik $\mathrm{NaOCl}$ ile, final irrigasyonda ise $5 \mathrm{ml} \% 17^{\prime}$ lik EDTA ve $5 \mathrm{~mL} \% 2.5^{\prime}$ lik $\mathrm{NaOCl}$ ile yıkandı ve kağıt konlarla kurulandı. Kanal içi medikamenti olarak kullanılacak saf kalsiyum hidroksit tozu 1:1 oranında distile su ile karıştırıldıktan sonra lentülo spiral (Dyna, Bourges,France) yardımı ile kök kanallarına uygulandı. Giriş kaviteleri, pamuk pelet ve kalınlığı 3-4 mm olacak şekilde Cotosol (Coltosol, Colten, Langenau, Almanya) geçici dolgu maddesiyle kapatıldı ve tüm örnekler $37{ }^{\circ} \mathrm{C}^{\prime}$ de $\% 100$ nemli ortamda bekletildi. 1 hafta sonra örnekler etüvden çıkartıldı ve kanal içi medikament önce F4 döner eğe ile çalışma boyunda aşağı ve yukarı hareketlerle, ardından ise farklı irrigasyon protokolleri ile kök kanallarından uzaklaştırıldı.

Çalışmada 4 deney ( $n: 15)$ ve 2 kontrol grubu (n:5) oluşturuldu. Pozitif kontrol grubunda kanal içi medikament uygulanmış örneklere herhangi bir irrigasyon protokolü uygulanmadı. Çalışmada oluşturulan gruplar aşağıdaki gibi sıralanmıştır.

Grup 1 GSI (Geleneksel Şırınga ile İrrigasyon): Bu deney grubunda kök kanallarından kalsiyum hidroksiti uzaklaştırmak için 2.5 mL'lik şırınga ile (Ayset A.Ş. İstanbul, Türkiye) 27 G'luk yandan delikli endodontik irrigasyon iğnesi (KerrHawe SA, Bioggio, İsviçre) birlikte kullanıldı. İğne ucu çalışma boyundan $1 \mathrm{~mm}$ kısa olacak şekilde yerleştirildi ve kök kanalları sırasıyla $2.5 \mathrm{~mL} \mathrm{NaOCl}(\% 2.5), 2.5 \mathrm{~mL}$ EDTA (\%17) ve 2.5 $\mathrm{mL} \mathrm{NaOCl}(\% 2.5)$ solüsyonlarının her birisi ile 1 dakika süresince aktif olarak yıkamanın ardından kullanılan solüsyonun kanal içerisinde 1 dakika bekletilmesi ile pasif irrigasyon işlemi gerçekleştirildi.

Grup 2 Vibringe (Sonik İrrigasyon): Bu çalışma grubunda Vibringe sonik irrigasyon cihazı, 27 G'luk yandan delikli endodontik irrigasyon iğnesi (KerrHawe SA, Bioggio, İsviçre) ile birlikte kullanıldı. İğne ucu çalışma boyundan $1 \mathrm{~mm}$ kısa olacak şekilde yerleştirildi. Kök kanalları sırasıyla $2.5 \mathrm{~mL} \mathrm{NaOCl} \mathrm{( \%}$ 2.5), $2.5 \mathrm{~mL}$ EDTA (\%17) ve $2.5 \mathrm{~mL} \mathrm{NaOCl}$ (\% 2.5) ile 1 dakika boyunca sonik enerji uygulanarak aşağıyukarı hareketlerle yıkandı. Her aktivasyonun ardından kullanılan irrigasyon solüsyonu kök kanalında 1 dakika bekletilerek pasif irrigasyon işlemi uygulandı.

Grup 3 EndoVac (Apikal Negatif Basınçlı İrrigasyon): Bu çalışma grubunda EndoVac system ekipmanlarından eksternal çapı ISO \#32 ve uç kısmında 12 adet mikroskobik delik bulunan mikro kanül ucu kullanıldı. Uç, üretici talimatları doğrultusunda çalışma boyunda yerleştirildi ve $2.5 \mathrm{~mL} \mathrm{NaOCl}$ (\% 2.5), 2.5 $\mathrm{mL}$ EDTA (\%17) ve $2.5 \mathrm{~mL} \mathrm{NaOCl}$ (\% 2.5) sırasyla 1 dakika boyunca ajite edildi. Her aktif irrigasyonun ardından kullanılan irrigasyon solüsyonu kök kanalında 1 dakikalık bekletilerek pasif irrigasyon uygulandı.

Grup 4 PUI (Pasif Ultrasonik İrrigasyon): Bu çalışma grubunda kök kanallarından kalsiyum hidroksit uzaklaştırma işlemi için piezoelektrik bir ünit ve (50\60 Hz, 25VA, EMS, Geneva, İsviçre) \#15 paslanmaz çelik bir eğeden (Varios $U$ file; Nakanishi, Inc. Tochigi, Japonya) yararlanıldı. Cihaz, üreticilerin talimatları doğrultusunda $1 / 2$ güç ayarına ayarlandı ve çalışma boyundan $1 \mathrm{~mm}$ kısa olarak şekilde yerleştirildi. Ardından kök kanalları sırası ile $2.5 \mathrm{~mL} \mathrm{NaOCl}$ (\% 2.5), $2.5 \mathrm{~mL}$ EDTA (\%17) ve $2.5 \mathrm{~mL} \mathrm{NaOCl} \mathrm{( \%}$ 2.5) solüsyonlarının herbiri ile 1 dakika boyunca ultrasonik eğenin ucu kanal duvarlarına temas etmeksizin aşağı yukarı hareketlerle aktif olarak yıkandı. Her aktif irrigasyonun ardından 1 dakika bekleme suretiyle pasif irrigasyon uygulanarak işlem tamamlandı.

Tüm deney gruplarında toplamda 3 dakika aktif, 3 dakika pasif olmak üzere toplam 6 dakika irrigasyon işlemi uygulandı. Tümgruplarda eşit hacimde irrigasyon solüsyonu kullanılmasına dikkat edildi. İrrigasyon işlemleri tamamlandıktan sonra kök kanalları $2.5 \mathrm{~mL}$ distile su ile yıkandı ve kağıt konlarla kurulandı. 


\section{Taramalı Elektron Mikroskobu İncelemesi}

Her bir kök bukkal ve lingual yönlerde paralel oluklar oluşturularak iki parçaya ayrıldı. Mikroskobik analiz için her bir kökün en uygun yarım parçası seçildi ve apikalden $0-4$, $4-8$ ve $8-12 \mathrm{~mm}$ uzaklıklarda işaretlemeler yapıldı. Örnekler $15 \mathrm{KV}$ altında, x 50 ve x 1000 büyütme kullanarak birbirinden bağımsız ve SEM morfolojisinin yorumlanmasında deneyimli olan iki endodonti uzmanı tarafından örneğin hangi deney grubuna ait olduğu bilinmeden incelenerek beş seviyeli skorlama sistemi ile skorlandı (Tablo 1 ). ${ }^{8}$

\section{İstatistiksel Analiz}

Elde edilen verilerin istatistiksel analizi SPSS 21 paket programı ile Kruskal Wallis $(p<0.05)$ testi ve gruplar arası anlamlı farkların bulunduğu durumlarda ikişerli grup karşılaştırmaları için Mann Whitney $U$ testi kullanılarak hesaplandı. edildi $(p<.0001)$ (Şekil 1) Vibringe, EndoVac ve PUI tekniklerinin etkinlikleri ise kanal üçlü bölgelerine göre anlamlı değişkenlik göstermedi.(p >0.05) (Şekil 2, Şekil 3, Şekil 4)

Tablo 2. Deney Grupları ve Bölgelere Göre Kalsiyum Hidroksit Skor Dağııımı

\begin{tabular}{cccccc}
\hline & \multirow{2}{*}{ Bölge } & \multicolumn{5}{c}{ Skor } \\
& & 2 & 3 & 4 & 5 \\
\hline \multirow{3}{*}{ Grup 1 (GSI) } & Koronal & 4 & 9 & 0 & 0 \\
& Orta & 3 & 8 & 4 & 0 \\
& Apikal & 0 & 2 & 10 & 3 \\
\hline \multirow{3}{*}{ Grup 2 (Vibringe) } & Koronal & 4 & 2 & 1 & 0 \\
& Orta & 5 & 1 & 0 & 0 \\
& Apikal & 3 & 3 & 1 & 0 \\
\hline \multirow{3}{*}{ Grup 3 (Endovac) } & Koronal & 3 & 2 & 2 & 0 \\
& Orta & 5 & 2 & 2 & 0 \\
& Apikal & 4 & 2 & 0 & 0 \\
\hline \multirow{3}{*}{ Grup 4 (PUI) } & Koronal & 3 & 2 & 0 & 0 \\
& Orta & 2 & 2 & 0 & 0 \\
& Apikal & 4 & 2 & 0 & 0 \\
\hline
\end{tabular}

Tablo 1. Skorlama Sistemi

\begin{tabular}{ll}
\hline Kalıntı Gözlemlenmesi & Skor \\
\hline $\begin{array}{l}\text { Az miktarda kalsiyum hidroksit ile birlikte temiz kök kanal } \\
\text { duvarları }\end{array}$ & 1 \\
$\begin{array}{l}\text { Bir miktar kalsiyum hidroksit artığı } \\
\text { Kök kanallarının \% 50sinden daha azını kaplayan kalsiyum } \\
\text { hidroksit artığı }\end{array}$ & 2 \\
$\begin{array}{l}\text { Kök kanallarının \%50 sinden daha fazlasını kaplayan } \\
\text { kalsiyum hidroksit artığı }\end{array}$ & 3 \\
$\begin{array}{l}\text { Kök kanallarının tamamını kaplayan kalsiyum hidroksit } \\
\text { artığı }\end{array}$ & 4 \\
\hline
\end{tabular}

\section{BULGULAR}

Mevcut çalışmada gözlem içi tutarlıı̆ın $(0,808$ $\leq \mathrm{Kw} \leq 0,904)$ neredeyse mükemmel seviyede olduğu tespit edildi. Gözlemciler arasındaki uyum ise $(0,701 \leq$ $\mathrm{Kw} \leq 0,811)$ sağlam seviyede bulundu. Her bir deney grubuna ait skor değerleri Tablo 2 de gösterilmiştir.

Oluşturulan deney gruplarında kullanılan yöntemlerin hiçbirisiyle kalsiyum hidroksit medikamenti kök kanallarından tam olarak uzaklaştııılamadı. Bununla birlikte, GSI yönteminin kullanıldığı deney grubunda diğer gruplara göre anlamlı derecede fazla kalsiyum hidroksit artı̆ı tespit edilirken $(p<0.0001)$ Vibringe, EndoVac ve PUI grupları arasında ise istatistiksel olarak anlamlı fark gözlemlenmedi ( $p>0.05$ ).

Her bir tekniğin koronal, orta ve apikal üçlü bölgelerindeki etkinliği ayrı ayrı değerlendirildiğinde ise, GSI yönteminde diğer bölgelere oranla apikal üçlü bölgesinde etkinliğin anlamlı derecede azaldığı tespit

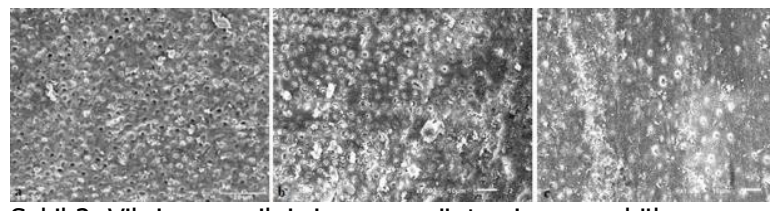

Şekil 2. Vibringe sonik irrigasyon yöntemi sonrası kök kanallarındaki kalsiyum hidroksit artığı (x1000 büyütme) a) koronal (skor 4) b) orta (skor 5) c) apikal (skor 4).

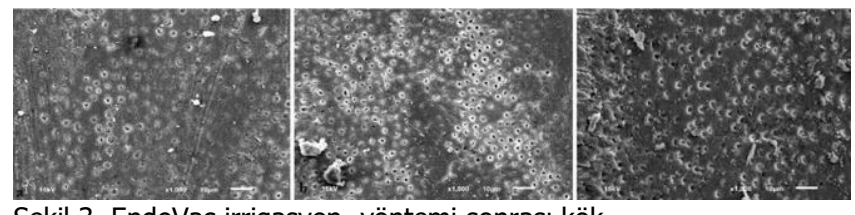

Şekil 3. EndoVac irrigasyon yöntemi sonrası kök kanallarındaki kalsiyum hidroksit artığı (x1000) (a) koronal (skor 4); (b) orta (skor 3); (c) apikal (Skor 2). 


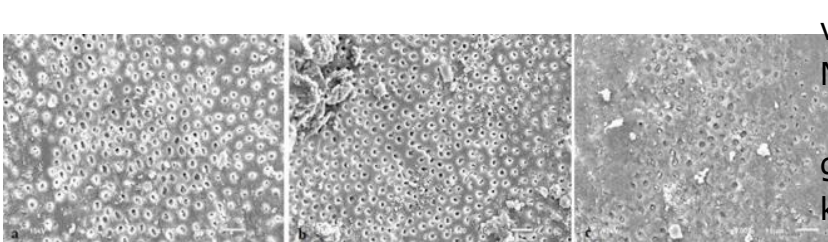

Şekil 4. Pasif Ultrasonik irrigasyon yöntemi sonrası kök kanallarındaki kalsiyum hidroksit artı̆̆ı (x1000 büyütme) a) koronal (skor 1) b) orta (skor 2) c) apikal Skor (3).

\section{TARTIŞMA}

Kalsiyum hidroksit antibakteriyel, antirezorbtif ve doku çözücü özelliklerinden dolayı kullanımı en çok tercih edilen kanal içi medikamenttir. Yüksek $\mathrm{PH}$ özelliği ile bakteri membran ve duvarlarında yıkıcı etki yaratarak kök kanal sisteminde bakteri eliminasyonunu sağlar. ${ }^{17}$ Ancak bu materyalin kullanımı kadar etkin bir şekilde uzaklaştırılabilmesi de tedavi başarısı açısından önemli yer tutar. Kök kanal sisteminden etkin şekilde uzaklaştırılamayan kalsiyum hidroksitin, patların dentin tübüllerine penetrasyonunu engellediği ve fiziksel özelliklerini bozduğu bilinmektedir. ${ }^{18} \mathrm{Bu}$ sebeple kalsiyum hidroksitin kök kanal dolumundan önce etkin bir şekilde uzaklaştırılması gerekmektedir.

Endodontide, mekanik preperasyonlar sırasında kullanılan yardımcı kimyasal maddeler arasında en sıklıkla sodyum hipoklorit $(\mathrm{NaOCl})$ yer almaktadır. Geniş bir mikrop spektrumunu yok etme ve kök kanal preperasyon sonrası kalan artık kollajen parçalar gibi organik içerikleri çözebilme yeteneğine ragmen, inorganik materyalleri çözebilme kabiliyeti yetersizdir. ${ }^{19}$ $\mathrm{Bu}$ nedenle pek çok endodonti uygulamasında EDTA gibi şelatör ajanlarla birlikte kullanımı tavsiye edilmiştir. ${ }^{20,}{ }^{21} \mathrm{NaOCl}$, ardından \% 17 EDTA ve son bir $\mathrm{NaOCI}$ yıkaması yaygın olarak kullanılan bir final irrigasyon protokolüdür. ${ }^{22-24}$ İşlem, $\mathrm{NaOCl}$ ile artık organik doku parçaların uzaklaştırılmasının ardından EDTA ile smear tabakasının eliminasyonu ve tekrar $\mathrm{NaOCl}$ kullanımı ile hidroksil iyonlarının dentin tübüllerine penetrasyonun artmasını ve böylece antimikrobial etkinin kuvvetlenmesini amaçlar. ${ }^{23,} 25$ Bunun yanı sıra, son irrigasyonun EDTA ile bitirilmesinde demineralize edici etkisi sayesinde dentinin fizikokimyasal özelliklerini değiştirip tedavi sonrası endodontik enfeksiyonlarla ilişkili bir bakteri olan Enterococcus faecalisin dentin duvarına kolaylıkla tutunabileceği ideal bir ortam meydana getirdiği rapor edilmiştir. ${ }^{26} \mathrm{Bu}$ nedenle bu çalışma, yaygın kullanılan ve önceki çalışmalarda da uygulanan $\mathrm{NaOCl}$-EDTA$\mathrm{NaOCl}$ final irrigasyon prosedürü ile gerçekleştirilmiştir. Şimdiki çalışmada kullanılan geleneksel ve güncel farklı irrigasyon tekniklerinin etkinliği, tüm kanal üçlü bölgelerinin toplam ortalama skorları hesaba katılarak değerlendirildiğinde, GSI yöntemi tüm gruplar içerisinde en başarısız yöntem olarak tespit edilmiştir. Bununla birlikte yöntemin etkinliğinin koronalden apikale doğru azaldığı ve kalan kalsiyum hidroksit miktarında da artış gözlemlenmiştir. GSI hala yaygın olarak kullanılan bir yöntem olmasına rağmen, kök kanallarının özellikle apikal üçlü bölgesinde temizleme etkinliğinin yeterli olmadığı bu çalışmanın yanısıra daha önce yapılan pek çok çalışmayla da tespit edilmiştir. ${ }^{27,}{ }^{28} \mathrm{Bu}$ sonucun ortaya çıkmasında 'vapor lock etkisi' adı verilen fenomenin etkili olduğu söylenebilir. Öyle ki, bu etkide kök kanalları ve kanül ucu arasında sıkışan hava nedeniyle irrigasyon solüsyonunun bölgeye akışı sağlanamamakta ve temizleme işleminin yapılabilmesi de zorlaşmaktadır. ${ }^{29}$ Bununla birlikte, apikal bölgenin hacim olarak dar olması ve daha az şelatör ajanını bağlayabilmesi de debridman etkinliklerinin azalmasına neden olmuş olabilir. $^{30}$

Bununla birlikte, elde edilen verilere göre, apikalde negatif basınçlı irrigasyon prensibine göre çalışan EndoVac'ın istatistiksel olarak anlam ifade etmemesine rağmen apikal üçlüde göstermiş olduğu etkin sonuç, negatif basınç yardımı ile irrigant akımında meydana gelen türbülansa ve bu çalışma prensibi sayesinde "Vapor Lock" etkinin önlenebilmesine atfedilebilir. ${ }^{31}$ Ayrıca, çalışma boyuna yerleştirilen mikrokanülde bulunan deliklerin vakum altında debris ve smearın yanısıra kalsiyum hidroksit parçalarını da aspire etmesi sayesinde temizlik etkinliğinde artış sağlanmış olabilir. ${ }^{34}$ Ancak, aspirasyon sırasında mikrokamül filtre deliklerinin büyük parçalar tarafından tıkanması ve ileri aşamalarda temizlik işlevinin aksaması sistemin eksiklikleri arasında gösterilmektedir. ${ }^{36}$ Apikalde negatif basınçlı irrgasyon (EndoVac,) sonik (EndoActivator) ve ultrasonik (ProUltra) irrigasyon yöntemleri ile kalsiyum hidroksit uzaklaştırma etkinliğinin incelendiği bir çalışmada EndoVac apikalde kontol grubundan daha iyi sonuç vermesine ragmen, sonik irrigasyon cihazı Endoaktivatör'ün tüm bölgelerde en etkili sonucu gösterdiği rapor edildi. ${ }^{37} \mathrm{Bu}$ sonuç şimdiki çalışmanın bulgularından kısmen farklılık göstermektedir. Öyle ki, şimdiki çalışmada sonik

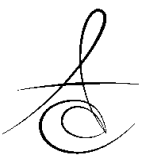


irrgasyon sistemi ile çalışan Vibringe, PUI ve EndoVac ile benzer temizleme etkinliği göstermiştir. Bu çalışmada bahsi geçen çalışmaya göre daha fazla hacimde ve sürede irrigasyon aktivaktivasyonun yapılması, aktivasyon yöntemlerinin MAF ile kombine edilmesi ve PUI yönteminde kullanılan eğenin boyutuna bağlı olarak meydana gelen tirbulans 38 kalsiyum hidroksit uzaklaştırma etkinliği arttırmış olabilir. Öyle ki yapılan bir araştırmada, sonik ve ultrasonik cihaz gibi titreşimle aktive olan sistemlerde uç kısmın düşük yer değiştirme genliğinin (1.2 \pm 0.1 $\mathrm{mm}$ ) yetersiz SIVı hareketi ile birlikte düşük kavitasyon etkisine neden olabileceği ve sonuç olarak yetersiz temizleme etkinliğinin oluşabileceği rapor edilmiştir. ${ }^{35}$ Yapılan pek çok çalışmada genel görüş yüksek frekansından dolayı ultrasonik irrigasyon yöntemlerinin (30 $\mathrm{kHz})$, sonik irrigasyon yöntemlerine kıyasla $(150 \mathrm{~Hz})$ kök kanallarında daha etkili debridman gerçekleştirdiği şeklindeydi. ${ }^{20,35, ~ 39, ~} 40$ Ancak bu görüşün aksine şimdiki çalışmada Vibringe sonik irrigasyon ile PUI benzer etkinlik göstermiştir. Bu bulgu Topçuoğlu ve ark. ${ }^{41}$ çalışmasının sonuçlarıyla benzerlik göstermektedir. Bu durum PUI'da kullanılan enerjinin 'vapour lock' adı verilen engelin aşılmasında yetersiz kalmasından kaynaklanabilir. Öyle ki, bazı araştırmalarda sonik veya ultrasonik aktivasyon sırasında aktive edilen eğenin apikaldeki gaz kabarcığı ile temas ettiği durumlarda akustik akım ve kavitasyon etkisinin ortadan kalktığı ve buna bağlı olarak yetersiz temizleme etkinliği meydana geldiği iddia edilmiştir. ${ }^{33,} 34$ Bununla birlikte yapılan çalışmalarda kullanılan kalsiyum hidroksit materyalinin aköz veya vizköz taşıyıcılarla kullanımının patın tübüllere diffüzyonuna ve erirliliğine; buna bağlı olarak kök kanallarından uzaklaştırımasına da etki ettiği bildirilmştir. ${ }^{42}$ Bu çalışmada kalsiyum hidroksit patının disitile su ile hazırlanması, kök kanallarından uzaklaştırılma etkinliğini kolaylaştırmış ve Vibringe sonik cihazın PUI ile benzer başarı sağlamasına neden olmuş olabilir. Bütün bunların yanında şimiki çalışmada, incelenen Vibringe sonik cihazın ergonomik olmayışı, adapte edilmiş şırınga sisteminin büyük olması, sistemi aktive etmek için devamlı aynı kuvvetin uygulanması gerekliliği ve kısa süreli de olsa aktivasyonu kesintiye uğrama intimali klinisyen tarafından kullanım zorluğu olarak belirtilmiştir.

Yapılan farklı araştırmalarda kök kanal duvarlarında kalan kalsiyum hidroksit miktarının tespiti için dijital fotoğraflar, steromikroskop, taramalı elektron mikroskop (SEM), Bilgisayarlı tomografi (CT), micro$C T$, spiral-CT gibi pek çok değişik yöntem kullanılmıştır. ${ }^{42-44}$ SEM görüntülemesi altında skorlama sistemi ile yapılan değerlendirme kalsiyum hidroksit uzaklaştırma etkinliğinin incelenmesinde güvenilir bir yöntem olarak rapor edilmiştir. ${ }^{21,46}$ Öyle ki, SEM görüntüleme ile birlikte skorlama sistemi, $\mathrm{CH}$ kalıntıları ile dentin duvarlarının renk benzerliklerinden dolayı ortaya çıkan ayırt edilebilme zorluklarını ortadan kaldırır. ${ }^{47} \mathrm{Bu}$ çalışmada örnekler SEM yardımıyla daha önceki çalışmalarda da uygulanan skorlama sistemlerine benzer bir sistem kullanılarak $\times 50$ ve $\times 1000$ büyütme altında incelenmiştir. Ancak yönteminin, kök kanallarının bütün olarak değerlendirilmeye imkan vermemesi ve yanlızca kesitsel incelemeye olanak sağlaması ${ }^{48}$ çalışmanın limitasyonları arasındanır ve mevcut sonuçları etkilemiş olabilir.

Bugüne kadar yapılan çalışmalarda ortak nokta, bu çalışmada da ulaşıldığı üzere hangi metod kullanıIırsa kullanılsın kanal içi medikamentin özellikle apikal üçlü bölgede kalıntı bırakmadan temizlenemediği şeklindedir. Bu durum apikal bölgedeki dentin tubullerinin sayıca azlığına, düzensizliğine ve bu bölgedeki anatomik varyasyonlara atfedilebilir.

\section{SONUC}

$\mathrm{Bu}$ in-vitro çalışmanın sınırları dahilinde, çalışmada kullanılan hiçbir yöntem ve cihaz kalsiyum hidroksit medikamentini kök kanallarından tam olarak uzaklaştıramamıştır. Üretici talimatlarına göre kullanılan Vibringe sonik sistem, kök kanallarında EndoVac ve PUI metodları ile benzer kalsiyum hidroksit uzaklaştırma etkinliği göstermiş ve bu üç yöntemin de GSI'dan daha başarılı olduğu tespit edilmiştir.

Banu Arıcıoğlu: ORCID ID: 0000-0002-1124-1905 Ömer Hatipoğlu: ORCID ID: 0000-0002-4628-8551

\section{KAYNAKLAR}

1. Hülsmann M, Peters OA, Dummer PM. Mechanical preparation of root canals: shaping goals, techniques and means. Endodontic Topics, 2005, 10: 30-76.

2. Law A, Messer $H$. An evidence-based analysis of the antibacterial effectiveness of intracanal medicaments. Journal of endodontics, 2004, 30: 689-94. 
3. Farhad A, Mohammadi Z. Calcium hydroxide: a review. International dental journal, 2005, 55: 293-301.

4. Gu L-s, Kim JR, Ling J, Choi KK, Pashley DH, Tay FR. Review of contemporary irrigant agitation techniques and devices. Journal of endodontics, 2009, 35: 791-804.

5. Clarkson RM, Moule AJ. Sodium hypochlorite and its use as an endodontic irrigant. Australian dental journal, 1998, 43: 250-256.

6. Van der Sluis L, Gambarini G, Wu M, Wesselink P. The influence of volume, type of irrigant and flushing method on removing artificially placed dentine debris from the apical root canal during passive ultrasonic irrigation. International endodontic journal, 2006, 39: 472-476.

7. Lambrianidis TP. Risk management in root canal treatment. Baskı. University Studio Press, 2001.

8. Pashley E, Nelson R, Pashley DH. Pressures created by dental injections. Journal of dental research, 1981, 60: 1742-1748.

9. Schoeffel GJ. The EndoVac method of endodontic irrigation: safety first. Dent Today, 2007, 26: 92, 94, 96 passim.

10. Nielsen BA, Baumgartner JC. Comparison of the EndoVac system to needle irrigation of root canals. Journal of endodontics, 2007, 33: 611-615.

11. Bradford C, Eleazer P, Downs K, Scheetz J. Apical pressures developed by needles for canal irrigation. Journal of endodontics, 2002, 28: 333335.

12. Weller RN, Brady JM, Bernier WE. Efficacy of ultrasonic cleaning. J Endod, 1980, 6: 740-743.

13. Gu LS, Kim JR, Ling J, Choi KK, Pashley DH, Tay FR. Review of contemporary irrigant agitation techniques and devices. J Endod, 2009, 35: 791804.

14. Sjögren U, Sundqvist G. Bacteriologic evaluation of ultrasonic root canal instrumentation. Oral surgery, oral medicine, oral pathology, 1987, 63: 366-370.

15. GRIFFITHS BM, Stock C. The efficiency of irrigants in removing root canal debris when used with an ultrasonic preparation technique. International endodontic journal, 1986, 19: 277-284.
16. Ricardo S, Nursasongko B. Comparison of Apical Third Cleanliness of Smear Layer Using Endoactivator $\AA$ and Vibringe $\AA$. Journal of International Dental \& Medical Research, 2016, 9.

17. Düzgün S, Topçuoğlu HS, Akpek F, Topçuoğlu G, Ulusan Ö, Ahmet A. Kök Kanalının Apikalinde Yapay Olarak Standardize Edİlmiş Oluktan Kalsiyum Hİdroksitin Uzaklaştırılmasında Qmix Solüsyonunun Etkinliği. Atatürk Üniversitesi Diş Hekimliği Fakültesi Dergisi, 2017, 27: 94-99.

18. Hosoya N, Kurayama $H$, Iino F, Arai T. Effects of calcium hydroxide on physical and sealing properties of canal sealers. International endodontic journal, 2004, 37: 178-184.

19. Ring KC, Murray PE, Namerow KN, Kuttler S, Garcia-Godoy F. The comparison of the effect of endodontic irrigation on cell adherence to root canal dentin. Journal of endodontics, 2008, 34: 1474-1479.

20. Rödig T, Bozkurt M, Konietschke $F$, Hülsmann M. Comparison of the vibringe system with syringe and passive ultrasonic irrigation in removing debris from simulated root canal irregularities. Journal of endodontics, 2010, 36: 1410-1413.

21. Salgado RJC, Moura-Netto C, Yamazaki AK, Cardoso LN, de Moura AAM, Prokopowitsch I. Comparison of different irrigants on calcium hydroxide medication removal: microscopic cleanliness evaluation. Oral Surgery, Oral Medicine, Oral Pathology, Oral Radiology, and Endodontology, 2009, 107: 580-584.

22. de Oliveira RL, Guerisoli DM, Duque JA, Alcalde MP, Onoda HK, Domingues FHF, Vivan RR, Duarte MA. Computed microtomography evaluation of calcium hydroxide-based root canal dressing removal from oval root canals by different methods of irrigation. Microscopy research and technique, 2019.

23. Moreira DM, Almeida JFA, Ferraz CCR, de Almeida Gomes BPF, Line SRP, Zaia AA. Structural analysis of bovine root dentin after use of different endodontics auxiliary chemical substances. Journal of endodontics, 2009, 35: 1023-7. 
24. Neelakantan P, Sharma S, Shemesh H, Wesselink $P R$. Influence of irrigation sequence on the adhesion of root canal sealers to dentin: a Fourier transform infrared spectroscopy and push-out bond strength analysis. Journal of endodontics, 2015, 41: 1108-1111.

25. Saif S, Carey CM, Tordik PA, McClanahan SB. Effect of irrigants and cementum injury on diffusion of hydroxyl ions through the dentinal tubules. Journal of endodontics, 2008, 34: 50-52.

26. Kishen A, Sum C-P, Mathew S, Lim C-T. Influence of irrigation regimens on the adherence of Enterococcus faecalis to root canal dentin. Journal of endodontics, 2008, 34: 850-854.

27. Yücel $A C$, Gürel $M$, Güler $E$, Karabucak $B$. Comparison of final irrigation techniques in removal of calcium hydroxide. Australian Endodontic Journal, 2013, 39: 116-121.

28. Faria G, Kuga MC, Ruy AC, Aranda-Garcia AJ, Bonetti-Filho I, Guerreiro-Tanomaru JM, Leonardo RT. The efficacy of the self-adjusting file and ProTaper for removal of calcium hydroxide from root canals. Journal of Applied Oral Science, 2013, 21: 346-350.

29. Gregory SD, Stevens MC, Pauls JP, Schummy E, Diab S, Thomson B, Anderson B, Tansley G, Salamonsen $\mathrm{R}$, Fraser JF. In vivo evaluation of active and passive physiological control systems for rotary left and right ventricular assist devices. Artificial organs, 2016, 40: 894-903.

30. Hülsmann M, Heckendorff $M$, Lennon A. Chelating agents in root canal treatment: mode of action and indications for their use. International endodontic journal, 2003, 36: 810-830.

31. Parente J, Loushine R, Susin L, Gu L, Looney SW, Weller R, Pashley DH, Tay F. Root canal debridement using manual dynamic agitation or the EndoVac for final irrigation in a closed system and an open system. International endodontic journal, 2010, 43: 1001-1012.

32. Desai $P$, Himel V. Comparative safety of various intracanal irrigation systems. Journal of endodontics, 2009, 35: 545-549.

33. Schoeffel GJ. The EndoVac method of endodontic irrigation, Part 3: System components and their interaction. Dentistry today, 2008, 27: 106, 10811.
34. Schoeffel GJ. The EndoVac method of endodontic irrigation, part 2--efficacy. Dentistry today, 2008, 27: 82, 84, 86-87.

35. Jiang L-M, Verhaagen $B$, Versluis $M$, van der Sluis LW. Evaluation of a sonic device designed to activate irrigant in the root canal. Journal of endodontics, 2010, 36: 143-146.

36. Shin S-J, Kim H-K, Jung I-Y, Lee C-Y, Lee S-J, Kim E. Comparison of the cleaning efficacy of a new apical negative pressure irrigating system with conventional irrigation needles in the root canals. Oral Surgery, Oral Medicine, Oral Pathology, Oral Radiology, and Endodontology, 2010, 109: 479484.

37. Alturaiki $S$, Lamphon $H$, Edrees $H$, Ahlquist $M$. Efficacy of 3 different irrigation systems on removal of calcium hydroxide from the root canal: a scanning electron microscopic study. Journal of endodontics, 2015, 41: 97-101.

38. Khademi A, Yazdizadeh $M$, Feizianfard $M$. Determination of the minimum instrumentation size for penetration of irrigants to the apical third of root canal systems. Journal of endodontics, 2006, 32: 417-20.

39. Capar ID, Ozcan E, Arslan H, Ertas H, Aydinbelge $H A$. Effect of different final irrigation methods on the removal of calcium hydroxide from an artificial standardized groove in the apical third of root canals. Journal of endodontics, 2014, 40: 451-454.

40. Gokturk H, Ozkocak I, Buyukgebiz F, Demir O. Effectiveness of various irrigation protocols for the removal of calcium hydroxide from artificial standardized grooves. Journal of Applied Oral Science, 2017, 25: 290-8.

41. Topçuoğlu HS, Aktı A, Topçuoğlu G, Düzgün S, Ulusan Ö, Akpek F. Effectiveness of conventional syringe irrigation, vibringe, and passive ultrasonic irrigation performed with different irrigation regimes in removing triple antibiotic paste from simulated root canal irregularities. Journal of conservative dentistry: JCD, 2016, 19: 323.

42. Balvedi R, Versiani M, Manna F, Biffi J. A comparison of two techniques for the removal of calcium hydroxide from root canals. International endodontic journal, 2010, 43: 763-8. 
43. Ballal N, Kumar S, Laxmikanth H, Saraswathi M. Comparative evaluation of different chelators in removal of calcium hydroxide preparations from root canals. Australian dental journal, 2012, 57: 344-348.

44. Lambrianidis T, Margelos J, Beltes P. Removal efficiency of calcium hydroxide dressing from the root canal. Journal of endodontics, 1999, 25: 8588.

45. Lambrianidis T, Kosti E, Boutsioukis C, Mazinis M. Removal efficacy of various calcium hydroxide/chlorhexidine medicaments from the root canal. International endodontic journal, 2006, 39: $55-61$.

46. Kuga MC, Tanomaru-Filho M, Faria G, Só MVR, Galletti T, Bavello JRS. Calcium hydroxide intracanal dressing removal with different rotary instruments and irrigating solutions: a scanning electron microscopy study. Brazilian dental journal, 2010, 21: 310-4.

47. Ribeiro EM, Silva-Sousa $Y T$, Souza-Gabriel $A E$, Sousa-Neto MD, Lorencetti KT, Silva SRC. Debris and smear removal in flattened root canals after use of different irrigant agitation protocols. Microscopy research and technique, 2012, 75: 781-90.

48. Faria G, Viola KS, Kuga MC, Garcia AJA, Daher VB, Leonardo MF, Tanomaru-Filho M. Effect of rotary instrument associated with different irrigation techniques on removing calcium hydroxide dressing. Microscopy research and technique, 2014, 77: 642-6.

\section{Yazışma Adresi}

Omer Hatipoglu

Sütçü İmam Üniversitesi

Diş Hekimliği Fakültesi

46000 Kahramanmaraş/TÜRKİYE

Tel: (344) 3003888

Cep: (+90 507) 8822249

E-mail:omerhtp@gmail.com, ohatipoglu@ksu.edu.tr 